\title{
Land use and soil development in southern Chile: Effects on physical properties
}

\author{
H. Fleige ${ }^{1 *}$, S. Beck-Broichsitter ${ }^{1}$, J. Dörner ${ }^{2,3}$, M.-O. Goebel ${ }^{4}$, J. Bachmann ${ }^{4}$, R. Horn ${ }^{1}$
}

${ }^{1}$ Institute of Plant Nutrition and Soil Science, Christian-Albrechts University zu Kiel, Olshausenstr. 40, 24118 Kiel, Germany. ${ }^{2}$ Instituto de Ingeniería Agraria y Suelos, Universidad Austral de Chile, Casilla 567, Valdivia, Chile. ${ }^{3}$ Centro de Investigación en Suelos Volcánicos, Universidad Austral de Chile.

${ }^{4}$ Institute of Soil Science, Leibniz University Hannover, Herrenhäuser Str. 2, 30419 Hannover Germany.

*Corresponding author: h.fleige@soils.uni-kiel.de

\begin{abstract}
Different physical properties of volcanic ash soils were investigated along a transect of $120 \mathrm{~km}$ from the western slope of the Central Cordilleras $\left(40^{\circ} 20^{\prime} \mathrm{S}, 72^{\circ} 06^{\prime} \mathrm{W}\right)$ to the eastern slope of the Costal Cordillera $\left(39^{\circ} 39^{\prime} \mathrm{S}, 73^{\circ} 11^{\prime} \mathrm{W}\right)$ in southern Chile with respect to the degree of soil development (Arenosol versus Andosol stage; Arenosol: young volcanic ash soil, free of clay, tephric properties, Andosol: older volcanic soil, clayey). The Andosols show a higher total pore volume and a higher field capacity, especially due to an increase in fine pores, than the Arenosols. Furthermore, the precompression stress ( $\mathrm{Pc}$ ) as a parameter for the mechanical soil strength is higher for Andosols despite of a lower bulk density. A land use (cropland, meadow, forest) dependent variation of the investigated parameters was less distinct for Andosols. A reduction of macropores and saturated hydraulic conductivity (ks) due to agriculture could be determined in the field, but in general the values are still on a high level with ks-values $>100 \mathrm{~cm} \mathrm{~d}^{-1}$. However, at higher stresses using an oedometer test the ks-values of the Andosols are highly negatively affected with values $<10 \mathrm{~cm} \mathrm{~d}^{-1}$. Aggregation is of major importance for soil stability of Andosols, whereas a homogenization of soil structure will lead to a distinct decrease of $\mathrm{Pc}$ of approx. 50\%.
\end{abstract}

Keywords: Andosol, Arenosol, hydraulic conductivity, precompression stress, stress strain behavior 


\section{Introduction}

According to the geography of Chile, which has a $\mathrm{N}-\mathrm{W}$ extension of more than $4.300 \mathrm{~km}$, four major soil zones are described (Casanova et al., 2013): (1) the hyper-arid to semi-arid zone, (2) the Mediterranean zone, (3) the rainy Patagonian zone, and (4) the insular Antarctic zone. Besides relief and climate, the volcanic activity in Chile is a major factor for the development of soils. Holocene volcanic ashes superposed wide areas of the original glacially formed countryside between the Andes (east) and the Costal Cordilleras (west). The soils can be described as young volcanic ash soils, in particular those close to the Andes, or well developed Andosols with varying physicochemical properties and mineralogical composition (Grez, 1977). Andosols in the longitudinal valley between the Andes and the Coastal Cordilleras are also described as "Trumaos" or as brown (Grez, 1977) or typical (Casanova et al., 2013) Andosols. These soils have good physical properties (e.g., low bulk density and good rooting, high water storage capacity and hydraulic conductivity, high humus contents) but some chemical limitations (e.g., high phosphate retention), and are used increasingly for grassland and crop cultivation at the expense of the primary, native forests $(\mathrm{Ca}-$ sanova et al., 2013).

It is well known that volcanic ash soils have specific physical properties. Along with the low bulk densities $\left(<0.9 \mathrm{~g} \mathrm{~cm}^{-3}\right)$ (Shoji et al., 1993; WRB, 2006) they usually have a well-defined and stable aggregation (Hoyos and Comerford, 2005; Zúñiga et al., 2015), which supports the development of inter- and intraaggregate voids. The latter is particularly true in a well-structured Andosol, where the presence of aggregates results in water retention curves having at least two inflection points (Poulenard et al., 2002; Woignier et al., 2008).
This allows for a high water and air storage capacity resulting in dynamic changes in soil water content depending on precipitation and evapotranspiration (Dörner et al., 2015). In this context, (macro) structure dependent properties have been widely studied (e.g., Ellies, 1988; Dec et al., 2012; Cuevas et al., 2014; Dörner et al., 2015); however, less research has been conducted on what happens when the soil structure is destroyed and/or homogenized (Seguel and Horn, 2005; Ivelic-Saez et al., 2015), which can help to understand the role of soil aggregation in soil physical functions of Andosols.

The agriculture in southern Chile has intensified in the past decades causing changes of hydraulic properties in the volcanic ash soils, and, coupled with high precipitation, they have created a risk of water erosion, which may lead to soil degradation (Ellies and Hartge 2000). Even though Andosols show a high resistance and resilience against mechanical loading (Dörner et al., 2011), the development of agriculture accompanied by intensive soil tillage and compaction by heavy machines may lead to major changes in soil structure and pore functions with negative environmental effects (e.g. Ellies and Horn, 1996; Ellies et al., 2000; Bachmann et al., 2006; Dec et al., 2012).

The aim of this study was to evaluate the relationship between physical, hydraulic, and mechanical properties of volcanic ash soils in the Mediterranean zone in southern Chile. In order to reach this aim, we analyzed pore size distribution, saturated hydraulic conductivity, and precompression stress and conducted additional consolidation tests to determine the effects of stress application in combination with a given soil structure on those parameters. 
The main questions are: How susceptible are different volcanic ash soils with primarily low bulk densities to (subsoil) compaction under different land uses? How does this affect pore functions and transport processes in these soils?

In particular, the following factors were studied:

i) soil development (young volcanic ash soils: Arenosols (Tephric) versus well developed volcanic ash soils: Andosols). Andosols are typical soils of southern Chile with high yield potentials. They are associated with young volcanic ash soils like Arenosols as a result of recently volcanic eruptions (tephric material). Depending on the level of soil formation, different physical properties can be expected.

ii) land use (Andosols, cropland, meadow and forest): The land use has changed tremendously in southern Chile over the last decades. Andosols are now mainly used as grasslands and for crop production. Depending on the land use, different effects on physical properties can be expected.

iii) soil structure (Andosols, meadow): It is well known, that aggregation is of major importance for soil stability in Andosols, depending on water suction. The effect of intact soil structure versus homogenization (e.g. due to kneading effects) on precompression stress was studied on two different textured Andosols using an oedometer device applying different stresses.

\section{Materials and Methods}

\subsection{Soils}

Four sites (U1, U2, U3, U4) are located along a transect that extends approximately $120 \mathrm{~km}$ from the western slope of the Central Cordilleras (Cordillera Central) (site U1 and site U2, 5 and $10 \mathrm{~km}$ distance to volcano Puyehue, $40^{\circ} 20^{\prime} \mathrm{S}, 72^{\circ} 06^{\prime} \mathrm{W}$ and $40^{\circ} 25^{\prime} \mathrm{S}$, $72^{\circ} 05^{\prime} \mathrm{W}$ ); a third site (U3) was across the Central Lateral Valley (Valle Central, close to Lago Ranco, $40^{\circ} 07^{\prime} \mathrm{S}, 72^{\circ} 28^{\prime} \mathrm{W}$ ); and a fourth site (U4) was at the eastern slope of the Costal Cordillera (Cordillera Costal, close to Valdivia, $39^{\circ} 39^{\prime} \mathrm{S}, 7^{\circ} 11^{\prime} \mathrm{W}$ ). The sites are characterized by different land use forms. Areas with cropland, meadow, or forest were selected to investigate site and land use dependent changes of soil properties. Soil samples were taken in 2011 and 2012. The classification of the soils was performed according to the Guidelines of the WRB (2006) and the Guidelines for Soil Description (FAO, 2006). Sites $\mathrm{U} 1$ and $\mathrm{U} 2$ are dominated by Haplic Arenosols (Tephric, Eutric), which are less developed soils (Ah/C horizon sequence) and free of clay (U1, U2). The soil texture is characterized as loamy sand with $75-80 \%$ sand and $20-25 \%$ silt contents. Site U3 is characterized by a Silandic Andosol (Eutric). Clay contents vary between 11 to $27 \%$ (meadow), $14-38 \%$ (forest), and $16-26 \%$ (cropland). The soil texture is a sandy loam, loam, and clayey loam. Site U4 is characterized by a Silandic Andosol (Eutric, Siltic). Clay contents vary from 20 to $36 \%$ (meadow), 19-26\% (forest), and $32-53 \%$ (cropland). The major soil texture is silty clay loam and silt loam. The sites U3 and U4 show an $\mathrm{Ah} / \mathrm{Bw} / \mathrm{C}$ horizon sequence and correspond to the socalled "trumao soils", which were described in detail by Grez (1977) regarding their chemical properties. These soils, which were developed from Holocene ashes, are allophanic and rich in organic material (Baumgarten et al., 2013).

\subsection{Total pore volume and pore size distribution}

Water retention curves were determined for undisturbed samples (cylinders, $100 \mathrm{~cm}^{3} ; n=5-13$ ). After water saturation by capillary rise from beneath, the samples were drained at matric potential values of -30 , $-60,-150,-300$ and $-500 \mathrm{hPa}$ (laboratory sand-bath and vacuum methods) as well as -5000 and -15000 $\mathrm{hPa}$ (overpressure method). Finally, the samples were 
dried at $105{ }^{\circ} \mathrm{C}$ for 24 hours to determine the bulk density. Pore size distribution was differentiated in wide macropores (wCP, up to $-60 \mathrm{hPa}$ ), narrow macropores (nCP, $-60--300 \mathrm{hPa})$, medium pores (MP, $-300--15.000 \mathrm{hPa})$, and fine pores $(\mathrm{FP}<-15.000 \mathrm{hPa})$ as indicated by Hartge and Horn (2014).

\subsection{Saturated hydraulic conductivity}

Saturated hydraulic conductivity (ks) was determined on vertically oriented, undisturbed soil samples (cylinders, $\left.100 \mathrm{~cm}^{-3} ; n=7-10\right)$ with the stationary hood permeameter according to Hartge and Horn (2014).

\subsection{Precompression stress}

Stress strain characteristics were analyzed for undisturbed and homogenized soil samples $\left(236 \mathrm{~cm}^{3} ; n=7-\right.$ 10) at different pressure steps and matric potentials $(-60,-300,-500 \mathrm{hPa})$ using a one dimensional confined compression test. The time settlement relationship was monitored with a strain gauge. The precompression stress $(\mathrm{Pc})$ value was determined according to the Casagrande (1936) method. For further information about the applied laboratory methods see Hartge and Horn (2014).

Additionally, undisturbed soil samples $\left(100 \mathrm{~cm}^{3}\right)$ were taken from the meadow sites to test the influence of various loads $(20,70,100,200,400$ and 700 $\mathrm{kPa}$ ) on porosity and $\mathrm{ks}$. The samples were drained at $-60 \mathrm{hPa}$ and stressed with the oedometer (for each load $n=5$ ) prior to the measurements. After water saturation by capillary rise, ks and total pore volume were determined.

\subsection{Classification of values}

The classification of total pore volume (very low $<30$, low 30-38, medium 38-46, high 46-54, very high $\geq 54$ Vol.- $\%$ ), air capacity $(\mathrm{AC}=$ wCP) (very low $<2$, low 2-5, medium 5-13, high 13-26, very high $\geq 26$ Vol.-\%), field capacity $(\mathrm{FC}=\mathrm{nCP}, \mathrm{MP}$ and $\mathrm{FP}$ ) (very low $<21$, low 21-30, medium 30-39, high 3948 , very high $\geq 48$ Vol.- $\%$ ), plant available water capacity $(\mathrm{AWC}=\mathrm{nCP}$ and $\mathrm{MP})$ (very low $<6$, low $6-14$, medium 14-22, high 22-30, very high $\geq 30$ Vol.-\%), and saturated hydraulic conductivity (ks) (very low $<1$, low $1-10$, medium $10-40$, high $40-100$, very high 100-300, extremely high $\geq 300 \mathrm{~cm} \mathrm{~d}^{-1}$ ) was performed according to the guidelines by Ad-hoc-AG Boden (2005) and Horn and Fleige (2003). Precompression stress (Pc) (very low $<30$, low 30-60, medium 60-90, high 90-120, very high $>120 \mathrm{kPa}$ ) was evaluated according to DVWK (1995) and Horn and Fleige (2003).

\subsection{Statistical analysis}

The statistical tests were done with the $\mathrm{R}$ package ( $\mathrm{R}$ Development Core Team, 2011). Average values of water content and matric potential were tested with ANOVA and Tukey HSD (Honestly Significant Difference). For ks values the geometrical mean was used since the data were not normally distributed (Ball, 1981). These data were tested with Kruskal-Wallis and Wilcoxon tests regarding significant differences.

\section{Results and Discussion}

\subsection{Total pore volume and pore size distribution}

\subsubsection{Arenosol versus Andosol stage}

A remarkable increase of pore volume $(\mathrm{PV})>15$ Vol.$\%$ from Arenosols (U1, U2) to more developed Andosols (U3, U4) was found (Figure 1). PV of $>70$ Vol.-\% for the Andosols can be classified as very high and it is also high to very high for the Arenosols. 


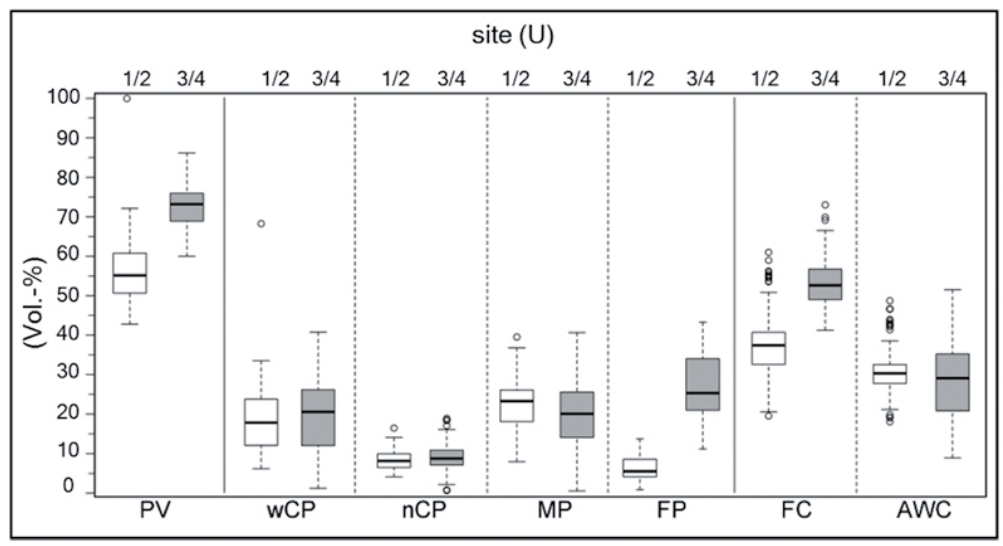

Figure 1. Total pore volume (PV), pore size distribution (wCP: wide coarse pores, $\mathrm{nCP}$ : narrow coarse pores, MP: medium pores, FP: fine pores), and soil hydraulic characteristics (FC: field capacity, AWC: plant available water capacity) of Arenosols (U1 and U2) and Andosols (U3 and U4) (all sites, $n$ total=316).

$\mathrm{AC}$ and $\mathrm{AWC}$ are high up to very high (20 and 30 Vol.-\%, respectively), which is similar to results obtained for a Typic Durudand (Dörner et al., 2011) and Duric Hapludand (Dörner et al., 2013). FC is very high for the finer textured Andosols with a higher fine pore fraction compared to the Arenosols (medium FC). Pore size distribution corresponds with values that are mentioned for Chilean trumaos by Grez (1977) and are in a range of 68-82 Vol.-\% PV. The pore size distributions are also in a similar order for coarse, medium, and fine pores due to a well defined intra and interaggregate porosity, which defines bimodal water retention curves with various water release ranges (Armas-Espinel et al., 2003; Miyamoto et al., 2003; Dörner et al., 2010). The results verify the findings of other authors considering the Andosols, but show furthermore the differences of physical properties depending on the soil development stage. The younger volcanic ash soil (Arenosol, tephric) has not yet evolved to a level which can be classified as Andosol, since the bulk density exceeds the critical value defined for Andosols of $0.9 \mathrm{~g} \mathrm{~cm}^{-3}$.

\subsubsection{Effect of land use (Andosols)}

The Andosols showed very high PV between 73 and 82 Vol.- $\%$ for the forest sites (Figure 2) that are in accordance with "andic properties" (WRB, 2006: bulk density $\left.<0.9 \mathrm{~g} \mathrm{~cm}^{-3}\right)$. A distinct decrease of PV down to 13 Vol.- $\%$ was observed for meadow and cropland in the topsoil and partially in the subsoil. The change of pore size distribution is mostly assigned to a loss of macropores, whereas the AC is classified as medium. Ellies et al. (2000) found that after deforestation of the primary, native forests, a quick main settlement occurs, which is followed by ongoing consolidation processes depending on subsequent land use. These structural changes lead to a decrease of (wide) coarse pores, which is in accordance with the findings of the present study. Simultaneously, the fraction of medium pores increased depending on the land use change and soil management intensity (Dörner et al., 2009), which was not found to be true for the samples analyzed in the present study. 


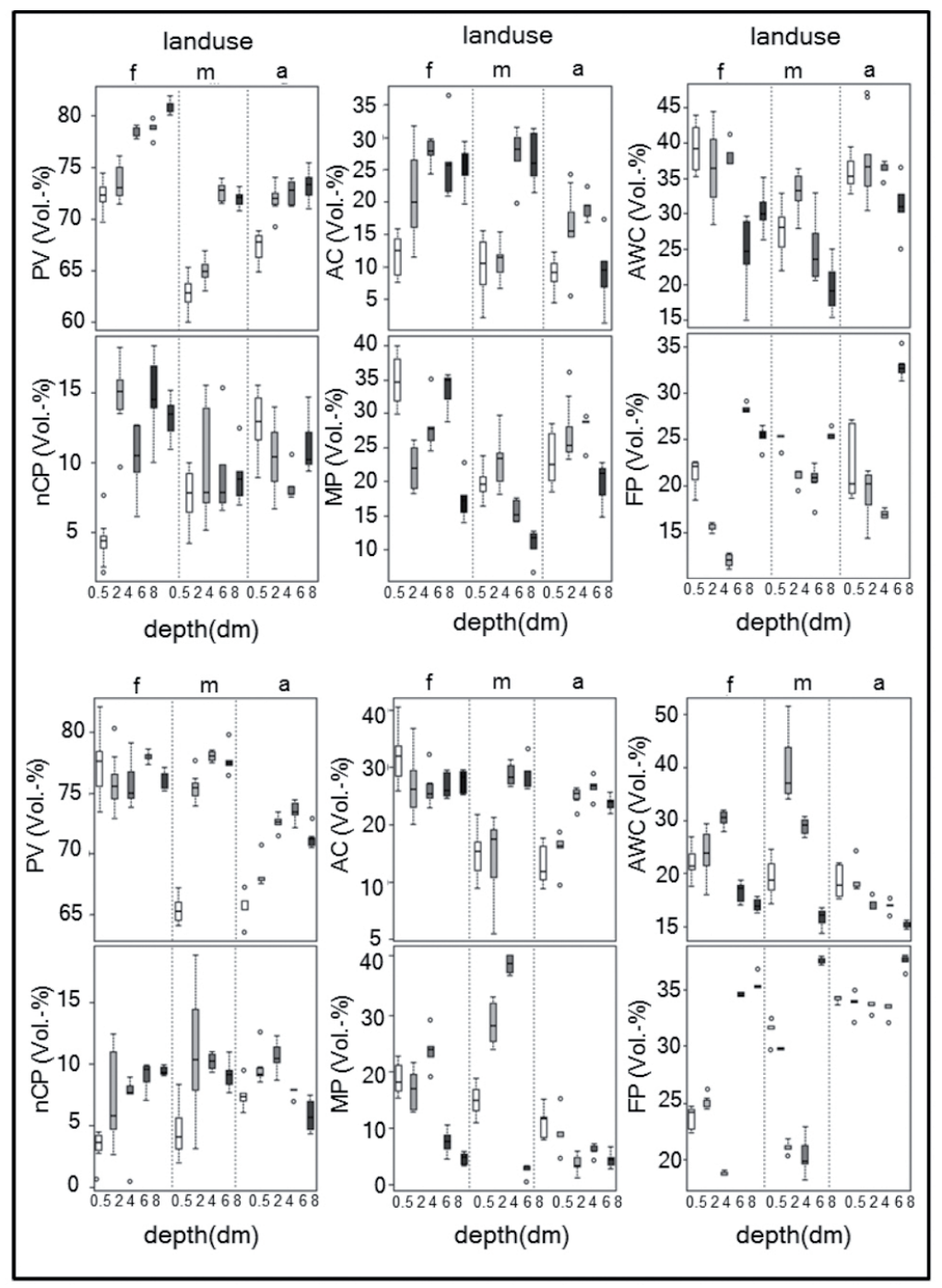

Figure 2. Effect of land use ( $\mathrm{f}=$ forest, $\mathrm{m}=$ meadow, $\mathrm{a}=$ cropland) on pore volume $(\mathrm{PV})$ and pore size distribution $(\mathrm{nCP}=$ narrow coarse pores, $\mathrm{MP}=$ medium pores, $\mathrm{FP}=$ fine pores) as well as air capacity $(\mathrm{AC}=$ wide coarse pores, $\mathrm{FC}=$ field capacity $=$ narrow coarse pores, medium pores and fine pores, $\mathrm{AWC}=$ plant available water capacity $=$ narrow coarse pores and medium pores) of Andosols (U3) (top) and U4 (bottom) ( $n$ total=206, $n=5-$ 13 per depth). 
Different pore size distributions of the Andosols can be ascribed to geogenic/pedogenic as well as anthropogenic reasons. The heterogeneity of texture and therefore of physical properties between the Andosols (see chap. 2.1) depends primarily on the distance to the volcanic sources and secondly on soil formation processes themselves (e.g. clay formation). Land use effects overlap these primarily differences which makes the interpretation of physical data more difficult. However, land use effects could be verified, especially in the top soil.

\subsection{Saturated hydraulic conductivity}

\subsubsection{Arenosol versus Andosol stage}

Both, Arenosols (U1, U2) and Andosols (U3, U4) showed high to extremely high ks values (Figure 3, top), which are typical for volcanic soils as reported by many authors (e.g., Warkentin and Maeda, 1980; Dörner et al., 2010; Cuevas et al., 2014).

The high ks of the Arenosols can be attributed to the primary pore system of the volcanic ashes, as this type of soil is characterized by a high fraction of primary macro pores. The finer textured Andosols show a higher fraction of secondary pores as a result of aggregation and a high shrinkage potential (Dörner et al., 2009), which consequently contributes to high ks values. Arenosols showed a good correlation between wCP and ks $\left(\mathrm{R}^{2}=0.71\right)$, whereas fine grained Andosols exhibited a less distinct relationship between those two parameters (Figure 3, below), which at the same time reflects differences in pore continuity as discussed in Dörner et al. (2010). Due to the properties of the tephric materials, the investigated young ash soils showed a high PV with a high fraction of macro pores. The edges of the ash particles can be rounded by deformation and shearing (Ellies and Funes, 1980; Ellies et al., 2000).
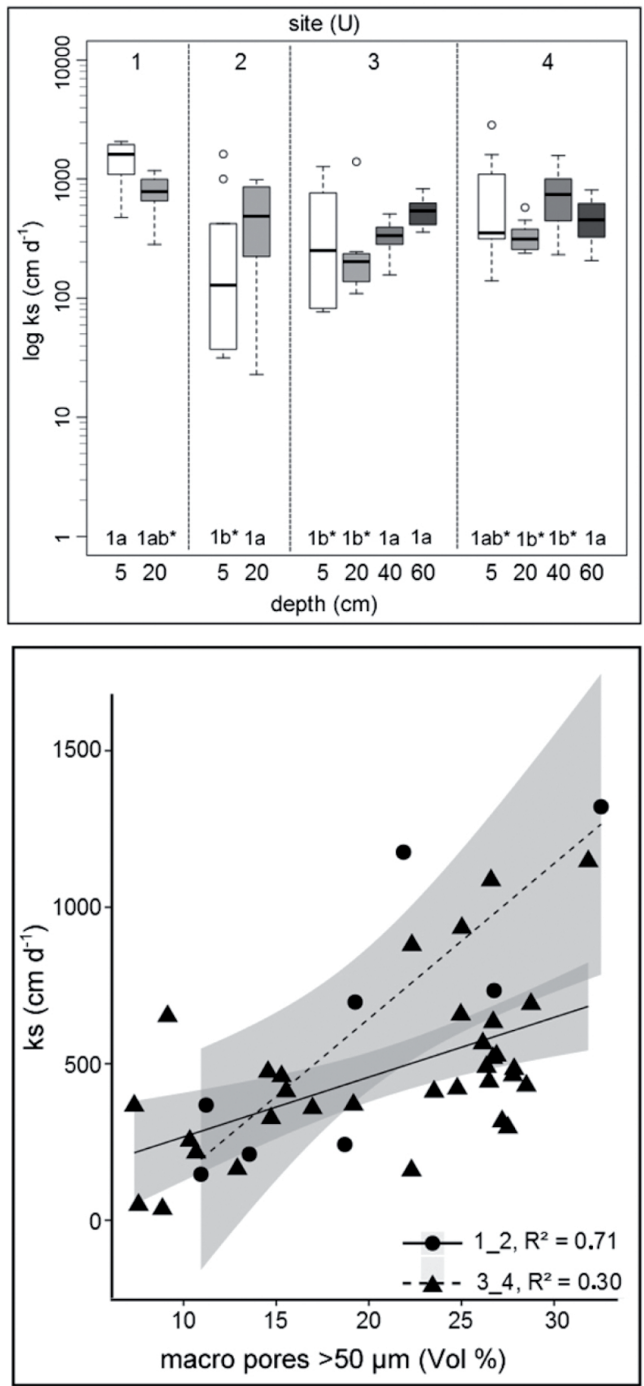

Figure 3. Top: Saturated hydraulic conductivity (ks) of Arenosols (U1 and U2) and Andosols (U3 and U4) (all sites). Different letters: Comparison of the sites $(\mathrm{P}<0.001)$, different numerals: Effect of depth $(\mathrm{P}<0.001)$; data with* show a level of significance of $\mathrm{P}<0.01$ ( $n$ total $=330, n=7-10$ per depth). Below: Correlation of saturated hydraulic conductivity (ks) and wide coarse pores of Arenosols (U1 and U2) and Andosols (U3 and U4) with the 95\% confidence interval (shaded), $n$ total=41 (U1, U2: $n=8$ and U3, U4: $n=33$ ). For the arithmetic mean values with $n=7-12$ were used. 
Thus, the ash particles can change their structure from the original asterisk structure to a more dense spherical structure by compaction, which then will result in a constant decrease of primary coarse pores and ks. The Silandic Andosols are soils with advanced structural development that play a major role in their hydraulic conductivity. Even after compaction and decrease of the wCP, the ks is still on a high level, but pore continuity will be reduced extremely after destroying the secondary pore system at higher stresses (see also oedometer test; Figure 8)

\subsubsection{Effect of land use (Andosols)}

The transport of gas in the soil depends on a continuous pore system, which is influenced by macropores (earthworm burrows, root channels, shrinkage cracks; e.g. Uteau et al., 2013) and may be reduced by consolidation (Mordhorst et al., 2012). In this context, a high fraction of coarse pores, is of major importance for the aeration of the root zone and to prevent soil wetness or stagnant water. The use of machines or animals on those sites will lead to soil compaction and simultaneously a loss of macropores. Figure 4 shows that there are effects on ks for meadow and cropland as a result of land use, but, in general, the values are still at a high level. Only for the topsoil of the cropland sites does ks show a decrease, and it can be classified as medium to high.

\subsection{Precompression stress}

\subsubsection{Arenosol versus Andosol stage}

For a characterization of the mechanical stability, the horizon specific Pc was determined. Pc shows how far soils can withstand loads by field traffic (e.g., Zink et al., 2010). The Pc values $(-60 \mathrm{hPa}$, moist soil) can be classified as low to medium for Arenosols and medium for Andosols (Figure 5, top).
Pc for Andosols are high despite a low bulk density for dry stages (-300 and $-500 \mathrm{hPa}$ ) (Figure 5, below, left) as also stated by Seguel and Horn (2005). Aggregation is of major importance for soil stability of Andosols, whereas a homogenization/destruction of aggregates will lead to a distinct decrease of Pc (Figure 5, below, right).
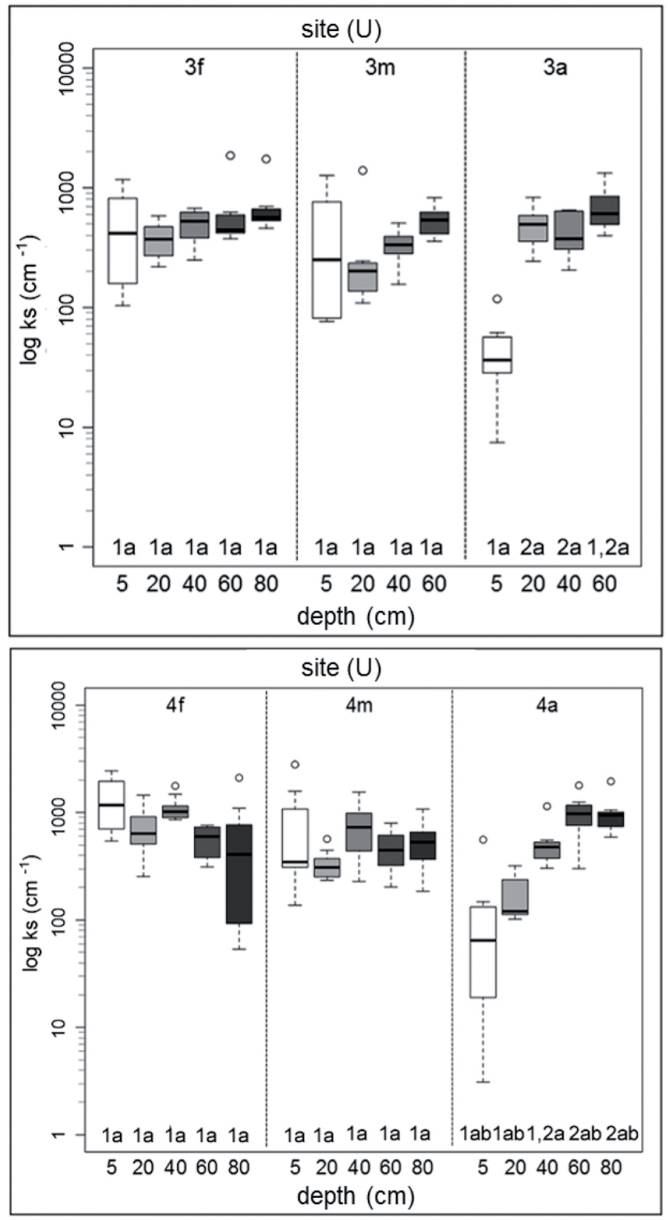

Figure 4. Effect of different land use ( $\mathrm{f}=$ forest, $\mathrm{m}=$ meadow, $\mathrm{a}=$ cropland) on saturated hydraulic conductivity (ks) of Andosols (U3 and U4). Different letters: Effect of land use $(\mathrm{P}<0.001)$, different numerals: effect of depth ( $n$ total $=118, n=7-10$ per depth). 

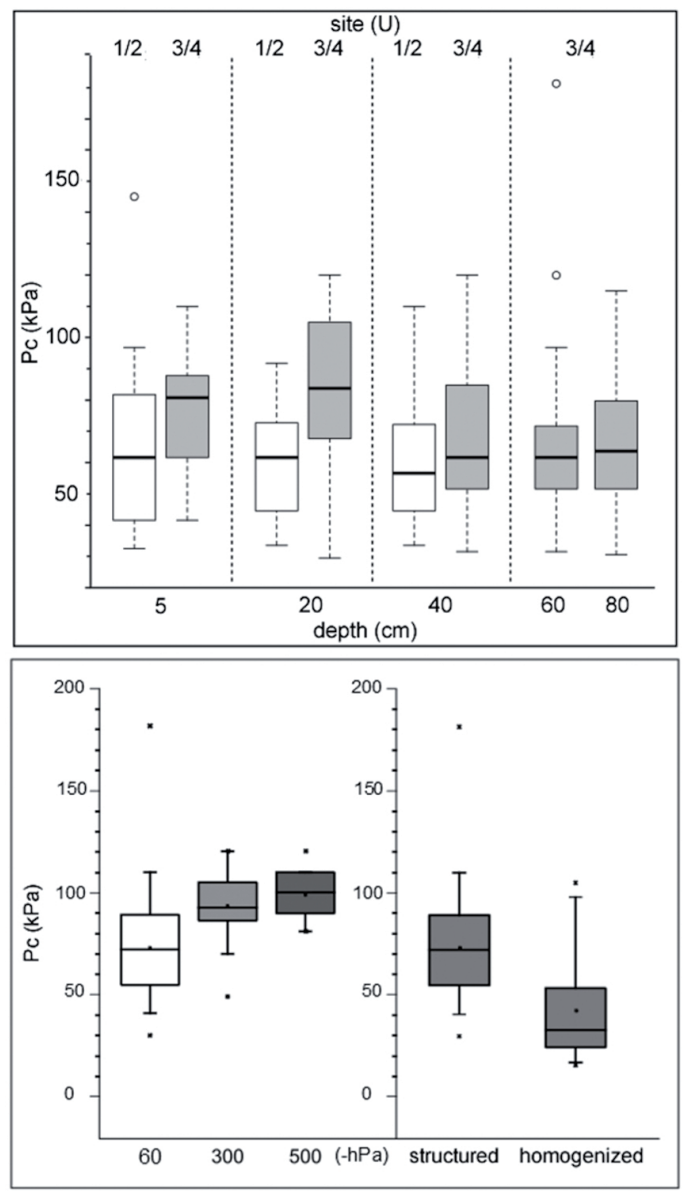

Figure 5. Top: Precompression stress (Pc, at $-60 \mathrm{hPa}$ matric potential) of Arenosols (U1 and U2) and Andosols (U3 and U4) (all usages, $n$ total=316). Below: Precompression stress (Pc) of Andosols (U3 and U4) as a function of matric potential (-60 hPa: $n=208$, $-300 \mathrm{hPa}: n=48,-500 \mathrm{hPa}: \mathrm{n}=21$ ) (left) and Pc (at -60 $\mathrm{hPa}$ matric potential) of Andosols in structured and homogenized condition (structured: $n=208$, homogenized: $n=48$ ); all usages (right).

\subsubsection{Effect of land use (Andosols)}

Andosols showed land use dependent differences in Pc down to the subsoil which are significant for site U4 (Figure 6). Pc can be classified as low to medium (forest soil) and medium to high (meadow, cropland) for moist conditions $(-60 \mathrm{hPa})$, which, in general, indicates a high aggregate stability as also stated by Zúñiga et al. (2015). Moreover, a thick root cover, like a felt, in the topsoil may additionally stabilize the forest soil (Ellies and Horn, 1996).
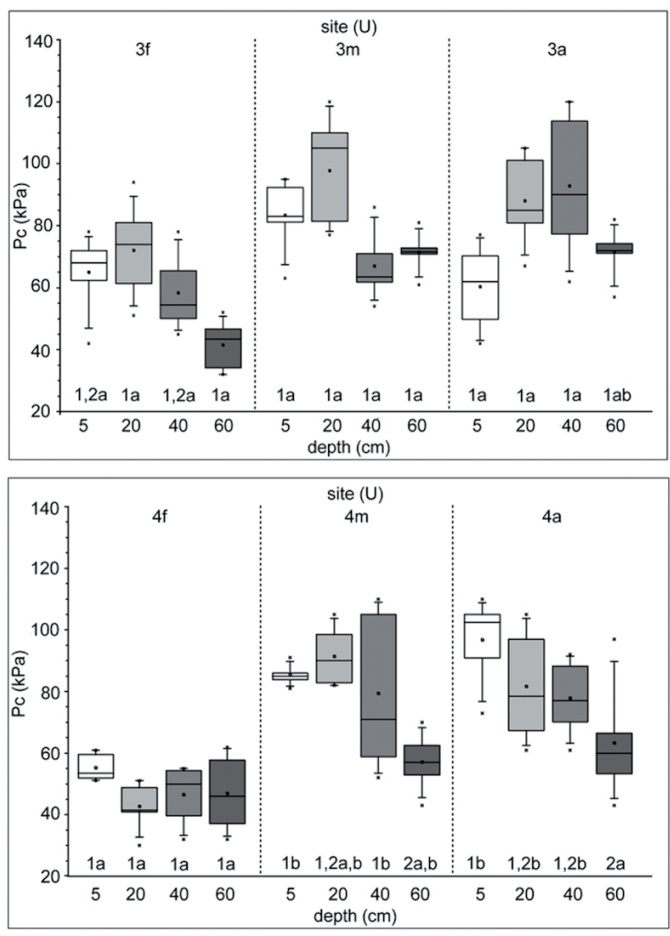

Figure 6. Effect of different land use (f=forest, $\mathrm{m}=$ meadow, $\mathrm{a}=$ cropland $)$ on precompression stress $(\mathrm{Pc}$, at $-60 \mathrm{hPa}$ matric potential) of Andosols (U3 and U4); Different letters: Effect of land use $(\mathrm{P}<0.001)$ different numerals: effect of depth $(\mathrm{P}<0.001)$; $(n$ total $=144)$. 
Pc is a measure of mechanical soil stability, but not for porosity (Arvidsson and Keller, 2004) or for hydraulic properties (Horn and Fleige, 2009). Consequently, the investigated soils showed only weak correlations between these parameters $\left(\mathrm{R}^{2} \leq 0.36\right)$. However, in general, a decrease in ks and PV is related to an increase in Pc (Figure 7). Also, the significance of bulk density for the assessment of stability is limited. In case of (very) low bulk density, the soils still showed high Pc, which is a result of their specific structure (Arenosols: primary asterisk structure of the ashes, Andosols: soil structure development/aggregation, secondary pores).

\subsection{The effects of stress application on changes in soil functions}

For determining the effects of mechanical loads on $\mathrm{PV}$ and ks, additional oedometer tests were conducted for undisturbed soil samples of the meadow sites of U3 and U4 (Andosols, $20 \mathrm{~cm}$ depth). The results reveal a reduction in $\mathrm{ks}$, if the applied stress exceeds $100 \mathrm{kPa}$ (equals average $\mathrm{Pc}$ at the $20 \mathrm{~cm}$ depth of meadow sites; compare Figure 6), although the total pore volume is still very high (Figure 8 ). That the pore continuity was distinctly reduced after increase of stress was already confirmed by Ellies and Horn (1996).

Oedometer tests for much denser loamy materials from soils derived from glacial till showed that stresses of $70 \mathrm{kPa}$ led to a harmful compaction regarding critical values of pore functions such as ks or AC (Gebhardt et al., 2009). In the present study, the forest sites showed much lower Pc values under wet conditions, whereas meadow and cropland sites showed higher Pc values (e.g., Seguel and Horn, 2005; Dörner et al., 2009). Only for high stresses low ks values were reached, which indicates a significant soil structure deformation.

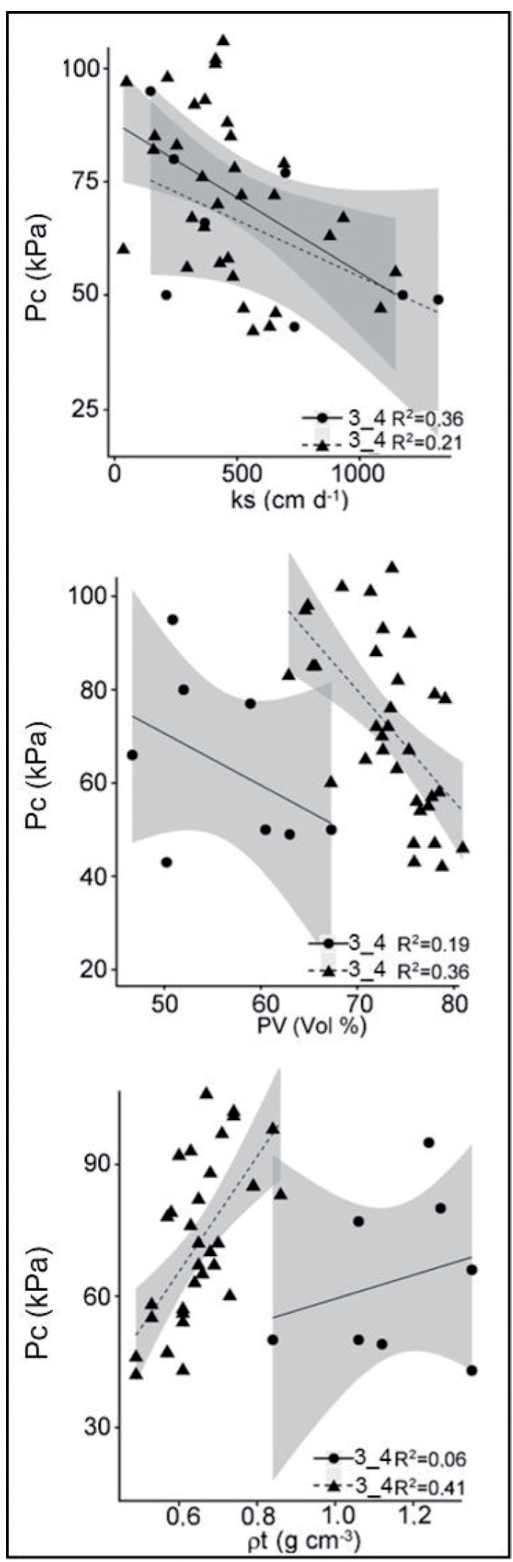

Figure 7. Correlation of precompression stress (Pc, at $-60 \mathrm{hPa}$ matric potential) and saturated hydraulic conductivity (ks), total pore volume (PV) and bulk density $(\rho t)$ of Arenosols (U1 and U2) and Andosols (U3 and U4) with the $95 \%$ confidence interval (shaded), $n$ total=41 (U1, U2: $n=8$ and U3, U4: $n=33$ ). For the correlation arithmetic mean values with $n=7-12$ were used. 


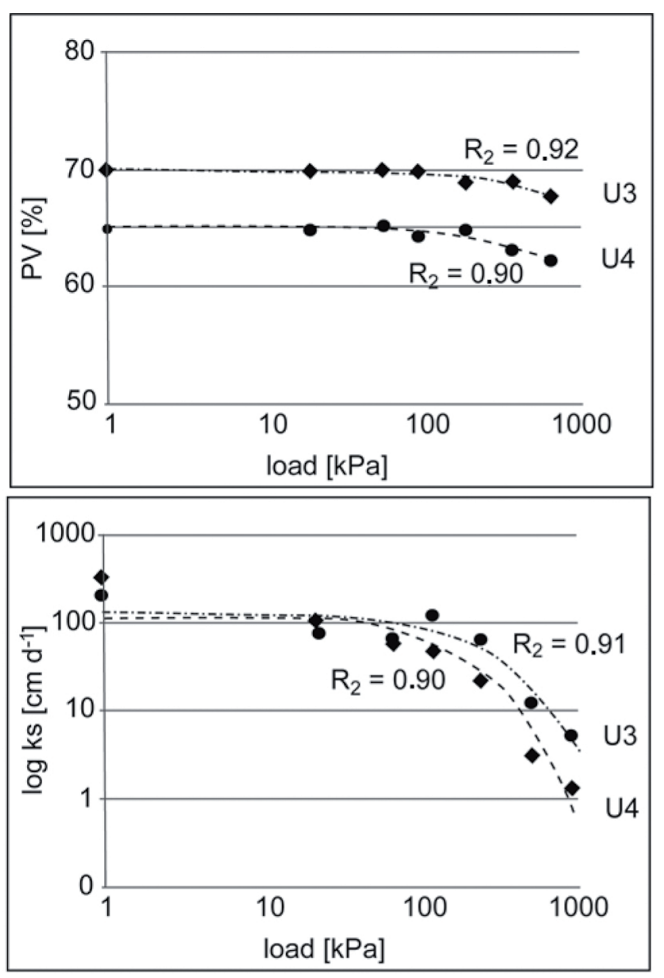

Figure 8. Effect of different stress on total pore volume (PV, top) and saturated hydraulic conductivity (ks, below) of Andosols (U3 and U4) (uniaxial confined compression device)

These results are relevant, because we have to consider that high loads are usual for Chilean agricultural and forestry soils as described by Ellies and Gayoso (1986), who mentioned stresses exceeding $500 \mathrm{kPa}$ for machines and values between 180 and $250 \mathrm{kPa}$ for animals. According to Seguel and Horn (2005), the critical stresses should not exceed 300 $\mathrm{kPa}$ for Andosols. But most probably already at 200 $\mathrm{kPa}$ positive pore water pressure will occur and be enhanced shear and homogenization processes

\section{Conclusions}

The results of this study showed differences concerning the physical properties of young, less developed Arenosols close to the volcano chain and more developed fertile Andosols. Soil development generates a higher precompression stress, total porosity, and volumetric water content at field capacity.

Soil compaction normally reduces air capacity, water permeability or total porosity as a consequence of exceeding the precompression stress. However, land use modifications are less pronounced than expected. The measured values do not reflect severe problems with respect to harmful subsoil compaction ( $\mathrm{ks}<10 \mathrm{~cm}^{-1}$, AC $<5$ Vol.- \%, see Zink et al., 2012) in the studied soils so far. The reason is that Andosols provide very favorable soil physical properties, primarily being far above the defined threshold values. Consequently, the question rises if these should be redefined for Andosols, e.g. with respect to yield functions.

Furthermore, it is known that volcanic ash soils have a great resilience capacity and can recover their functional integrity due to wetting and drying cycles. Shrinkage potential correlates negatively with increasing bulk density, and can thus be reduced as a consequence of soil compaction. Andosols react more sensitively to both hydraulic and mechanical stresses than Arenosols (e.g. Beck-Broichsitter et al. 2016).

However, it could be shown that at higher stresses (using an oedometer test) the saturated hydraulic conductivity of Andosols is highly negatively affected. Thus, lower hydraulic conductivity coupled with high rainfall intensities in southern Chile will favor runoff and erosion. The destruction of the asterisk structure of volcanic ashes in the Arenosol stage by deformation and shearing is irreversible, but they retain most of their hydraulic conductivity. A higher penetration resistance to roots in the Arenosols may be warrant further research. 


\section{Acknowledgements}

This project between Chile and Germany was funded by the German Research Foundation (DFG) (HO 911/45-1, BA 1359/12-1). Dr. José Dörner also thanks the Alexander von Humboldt Foundation for the research stay at the Christian Albrechts University of Kiel (Georg Foster Fellowship for Experienced Researchers). We wish to thank Prof. Dr. M.B. Kirkham (Kansas State University) for valuable discussions and for linguistic review of the paper.

\section{References}

Ad-hoc-AG Boden 2005. Bodenkundliche Kartieranleitung, 5. Edition, Hannover, Germany, p. 438.

Arvidsson, J., Keller, T. 2004. Soil precompression stress. II. A comparison of different compaction tests and stress-displacement behaviour of the soil during wheeling. Soil Till. Res. 77, 85-95.

Armas-Espinel, S., Hernandez-Moreno, J., MunozCapena, R., Regaldo, C. 2003. Physical properties of "sorriba" - cultivated volcanic soils from Tenerife in relation to andic diagnostic parameters. Geoderma. 117, 297-311.

Bachmann, J., Contreras, K., MacDonald, A. R., Hartge, K. H. 2006. Comparison of soil strength data obtained in situ with penetrometer and with shear-vane. Soil Till. Res. 87, 112-118.

Ball, B. C. 1981. A laboratory method to measure gas diffusion and flow in soil and other porous materials. J. Soil Sci. 32, 323-334.

Baumgarten, W., Dörner, J., Horn, R. 2013. Microstructural development in volcanic ash soils from South Chile. Soil Till. Res. 129, 48-60.
Beck-Broichsitter, S., Fleige, H., Goebel, M.-O., Dörner, J., Bachmann, J., Horn, R. 2016. Shrinkage potential and pore shrinkage capacity of differently developed volcanic ash soils under pastures in southern Chile. J. Plant Nutr. Soil Sci., DOI: $10.1002 /$ jpln.201600110.

Casagrande, A. 1936. The determination of preconsolidation load and its practical significance. Proc. of the 1st Int. Conf. Soil. Mech. Found Engl. Cambridge 3, 60-64.

Casanova, M., Salazar, O., Seguel, O., Luzio, W. 2013. The Soils of Chile. Springer, Dordrecht, 185 p.

Cuevas, J., Horn, R., Seguel, O., Dörner, J. 2014. Hydraulic conductivity variation in Chilean volcanic soils due to wheeling and management. J. Soil Sci. Plant Nutr. 13, 756-766.

Dec, D., Dörner, J., Balocchi, O., López, I. 2012. Temporal dynamics of hydraulic and mechanical properties of an Andosol under grazing. Soil Till. Res. 125, 44-51.

Dörner, J., Dec, D., Peng, X., Horn, R. 2009. Change of shrinkage behavior of an Andisol in southern Chile. Effects of land use and wetting/drying cycles. Soil. Till. Res. 106, 45-56.

Dörner, J., Dec, D., Peng, X., Horn, R. 2010. Effect of land use change on the dynamic behaviour of structural properties of an Andisol in southern Chile under saturated and unsaturated hydraulic conditions. Geoderma. 159, 189-197.

Dörner, J., Dec, D., Zúñiga, F., Sandoval, P., Horn, R. 2011. Effect of the land use change on Andosol's pore functions and their functional resilience after mechanical and hydraulic stresses. Soil Till. Res. 115-116, 71-79.

Dörner, J., Zúñiga, F., López, I. 2013. Short-term effects of different pasture improvement treatments on the physical quality of an Andisol. J. Soil Sci. Plant Nutr. 13, 381-399. 
Dörner, J., Dec, D., Peng, X., Horn, R. 2015. Effect of land use change on the dynamic behaviour of structural properties of an Andisol in southern Chile under saturated and unsaturated hydraulic conditions. Geoderma. 159, 189-197.

DVWK 1995. Gefügestabilität ackerbaulich genutzter Mineralböden. Teil I: Mechanische Belastbarkeit. DVWK-Merkblatt zur Wasserwirtschaft, No. 234, Bonn.

Ellies, A. 2000. Soil erosion and its control in Chile - An overview. Acta Geol. Hisp. 3-4, 279-284.

Ellies, A., Funes, M. 1980. Morphologie und Stabilität von Aggregaten aus chilenischen Vulkanasche-Böden. Z. Pflanzenernaehr. Bodenkd. 143, 530-536.

Ellies, A., Gayoso L. 1986. Die Bestimmung der Konsistenzgrenzen an einigen Vulkanaschenböden aus Südchile. Z. Pflanzenernaehr. Bodenkd. $149,1-8$.

Ellies, A. 1988. Mechanical consolidation in volcanic ash soils. In: J. Drescher, R. Horn, M. de Boodt (eds). Impact of Water and External Forces on Soil Structure. Catena Supplement 11. Catena, Cremlingen, pp: 87-92.

Ellies, A., Horn, R. 1996. Mechanische Druckfortpflanzung in vulkanischen Aschenböden bei unterschiedlicher Bewirtschaftungsweise. J. Plant Nutr. Soil Sci. 158, 113-120.

Ellies, A., Horn, R., Smith, R. 2000. Effect of management of a volcanic ash soil on structural properties. Int. Agrophysics. 14, 377-384.

FAO 2006. Guidelines for Soil Description. Rome, 4th edition, $95 \mathrm{p}$.

Gebhardt, S., Fleige, H., Horn, R. 2009. Effect of compaction on pore functions of soils in a Saalean moraine landscape in North Germany. J. Plant. Nutr. Soil Sci. 172, 688-696.
Grez, R. 1977. Nährelementhaushalt und Genese von Böden aus vulkanischen Aschen in Südchile. Freiburger Bodenkundliche Abhandlungen, No. $6,179 \mathrm{p}$.

Hartge, K. H., Horn, R. 2014. Die physikalische Untersuchung von Böden. 4. revised edition. Schweizerbart, Stuttgart, $178 \mathrm{p}$.

Hoyos, N., Comerford, N. B. 2005. Land use and landscape effects on aggregate stability and total carbon of Andisols from the Colombian Andes. Geoderma. 129, 268-278.

Horn, R., Fleige, H. 2003. A method for assessing the impact of load on mechanical stability and on physical properties of soils. Soil. Till. Res. 73, 89-99.

Horn, R., Fleige, H. 2009. Risk assessment of subsoil compaction for arable soils in Northwest Germany at farm scale. Soil. Till. Res. 102, 201-208.

Ivelic-Sáez, J., Zúñiga, F., Valle, S., López, I., Dec, D., Dörner, J. 2015. Functional resistance and resilience of the pore system of an Andisol exposed to different strategies of pasture improvement under sheep grazing. J. Soil Sci. Plant Nutr. 15, 663-679.

Miyamoto, T., Annaka, T., Chikushi, J. 2003. Soil aggregate structure effects on dielectric permitivity of an Andisol measured by time domain reflectometry. Vadose Zone J. 2, 90-97.

Mordhorst, A., Zimmermann, I., Peth, S., Horn, R. 2012. Effect of hydraulic and mechanical stresses on cyclic deformation processes of a structured and homogenized silty Luvic Chernozem. Soil Till. Res. 125, 3-13.

Poulenard, J., Bartoli, F., Burtin, G. 2002. Shrinkage and drainage in aggregates of volcanic soils: a new approach combining mercury porosimetry and vacuum drying kinetics. Eur. J. Soil Sci. 53, 563-574. 
R Development Core Team 2011. A language and environment for statistical computing. R Foundation for Statistical Computing. Vienna, Austria.

Seguel, O., Horn, R. 2005. Mechanical behavior of a volcanic ash soil (Typic Hapludand) under static and dynamic loading. Soil Till. Res. 82, 109-116.

Shoji, S., Nanzyo, M., Dahlgren, R. A. 1993. Volcanic Ash Soils. Genesis, Properties and Utilization. Developments in Soil Science 21. Elsevier, Amsterdam, $288 \mathrm{p}$.

Uteau, D., Pagenkemper, S., Peth, S., Horn, R. 2013. Root and time dependent soil structure formation and its influence on gas transport in the subsoil. Soil Till. Res. 132, 69-76.

Warkentin, B. P., Maeda, T. 1980. Physical and mechanical characteristics of Andisols. In: B. K. G. Theng (ed). Soils with Variable Charge. Society of Soil Science, New Zealand, pp. 281-301.
Woignier, T., Morell, M., Primera, J., Duffours, L. 2008. Correlation between large water content and fractal structure in volcanic soils. BALWOIS 2008 - Ohrid, Republic of Macedonia, 27-31. May 2008.

WRB 2006. World Reference Base for Soil Resources 2006. World Soil Resources Report No. 103. FAO, Rome.

Zink, A., Fleige, H., Horn, R. 2010. Load risks of subsoil compaction and depths of stress propagations in arable Luvisols. Soil Sci. Soc. Am. J. 74, 1733-1742.

Zink, A., Fleige, H., Horn, R. 2012. Verification of harmful subsoil compaction of Luvisols. Soil Till. Res. 114, 127-134.

Zuñiga, F., Ivelic-Sáez, J., López, I., Huygens, D., Dörner, J. 2015. Temporal dynamics of the physical quality of an Andisol under a grazing system subjected to different pasture improvement strategies. Soil Till. Res. 145, 233-241. 